\title{
BMJ Open A point prevalence cross-sectional study of healthcare-associated urinary tract infections in six Australian hospitals
}

\author{
Anne Gardner, ${ }^{1}$ Brett Mitchell, ${ }^{1,2}$ Wendy Beckingham, ${ }^{3}$ Oyebola Fasugba ${ }^{1}$
}

To cite: Gardner A, Mitchell B, Beckingham W, et al. A point prevalence cross-sectional study of healthcare-associated urinary tract infections in six Australian hospitals. BMJ Open 2014;4:e005099. doi:10.1136/bmjopen-2014005099

- Prepublication history and additional material is available. To view please visit the journal (http://dx.doi.org/ 10.1136/bmjopen-2014005099).

Received 20 February 2014 Revised 23 June 2014 Accepted 24 June 2014

CrossMark

For numbered affiliations see end of article.

Correspondence to Dr Anne Gardner; anne.gardner@acu.edu.au

\begin{abstract}
Objectives: Urinary tract infections (UTIS) account for over $30 \%$ of healthcare-associated infections. The aim of this study was to determine healthcare-associated UTI (HAUTI) and catheter-associated UTI (CAUTI) point prevalence in six Australian hospitals to inform a national point prevalence process and compare two internationally accepted HAUTI definitions. We also described the level and comprehensiveness of clinical record documentation, microbiology laboratory and coding data at identifying HAUTIs and CAUTIs.

Setting: Data were collected from three public and three private Australian hospitals over the first 6 months of 2013 .
\end{abstract}

Participants: A total of 1109 patients were surveyed. Records of patients of all ages, hospitalised on the day of the point prevalence at the study sites, were eligible for inclusion. Outpatients, patients in adult mental health units, patients categorised as maintenance care type (ie, patients waiting to be transferred to a long-term care facility) and those in the emergency department during the duration of the survey were excluded.

Outcome measures: The primary outcome measures were the HAUTI and CAUTI point prevalence.

Results: Overall HAUTI and CAUTI prevalence was $1.4 \%$ (15/1109) and 0.9\% (10/1109), respectively. Staphylococcus aureus and Candida species were the most common pathogens. One-quarter $(26.3 \%)$ of patients had a urinary catheter and fewer than half had appropriate documentation. Eight of the 15 patients ascertained to have a HAUTI based on clinical records ( 6 being CAUTI) were coded by the medical records department with an International Classification of Diseases (ICD)-10 code for UTI diagnosis. The Health Protection Agency Surveillance definition had a positive predictive value of $91.67 \%$ (Cl 64.61 to 98.51$)$ compared against the Centers for Disease Control and Prevention definition.

Conclusions: These study results provide a foundation for a national Australian point prevalence study and inform the development and implementation of targeted healthcare-associated infection surveillance more broadly.

\section{BACKGROUND}

Healthcare-associated infections (HAIs) have considerable medical consequences and

\section{Strengths and limitations of this study}

- This is the first study to compare two internationally accepted definitions in categorising patients with catheter-associated urinary tract infections, namely the Health Protection Agency and Centers for Disease Control and Prevention definitions.

- This study demonstrates the feasibility of conducting point prevalence surveys of healthcare-associated urinary tract infections in a standardised manner to facilitate comparisons over time within individual health facilities.

- A limitation of this study is that the survey was conducted in only six hospitals within two states and territories limiting the generalisability of the results. However, there were significant findings enabling recommendations for a future national point prevalence study to be made.

pose a significant problem for patient safety. ${ }^{1}$ A recent systematic review and meta-analysis of 220 international articles indicated that the prevalence and incidence of HAIs is $10 \%$ and $7 \%$ per 100 patients, respectively. ${ }^{2}$ Further, the prevalence of infected patients is $11 \%$ per 100 patients. $^{2}$ Fifty per cent of the reviewed prevalence studies stated magnitudes of infected patients higher than $10 \%$ per 100 patients. $^{2}$ The Centers for Disease Control and Prevention estimates that 1.7 million people develop HAIs and 100000 people die of HAI-related complications each year in the USA. ${ }^{3}$ The first European Union-wide Point Prevalence Survey (PPS) of HAIs and antimicrobial use in hospitals conducted in 2011-2012 estimated that on any given day, about 80000 patients have at least one HAI, that is, 1 in 18 patients in a European hospital has a HAI. ${ }^{4}$ The studies support the view that HAIs are the most common complication of hospitalisation. This concept is not new, as demonstrated in a landmark paper "To Err is Human: Building a Safer Health System" published in 1999 by the Institute of Medicine (IOM). ${ }^{5}$ 
However, these infections are a potentially preventable adverse event rather than an unpredictable complication and it is possible to significantly reduce the rate of HAIs through effective infection prevention and control. ${ }^{6}$

HAIs could be prevented by sustained, multifaceted infection prevention and control programmes, including the Hawthorne effect of surveillance. ${ }^{4}$ Although prospective active surveillance is considered to be the gold standard for surveillance, prevalence surveys are quite useful as they can provide baseline information about the occurrence and distribution of HAI, are generally easy to conduct, relatively inexpensive and not too time consuming. ${ }^{7} 8$ National surveillance of HAI has been introduced in North America and in many European countries, and national prevalence surveys of HAI are also increasingly common. ${ }^{8}$

Urinary tract infections (UTIs) account for more than $30 \%$ of HAIs reported by acute care hospitals. ${ }^{9}$ Virtually all healthcare-associated UTIs (HAUTIs) are caused by instrumentation of the urinary tract with $80 \%$ traced to the use of indwelling urinary catheters. ${ }^{10}$ The use of urethral catheters is very common with $15-25 \%$ of hospitalised patients receiving a short-term indwelling urinary catheter, hence high HAUTI rates are not surprising. ${ }^{11-14}$ Calculation of how many catheter-associated UTIs (CAUTIs) may be preventable varies considerably with estimates from unpublished data ranging from $17 \%$ to $69 \% .{ }^{15}$ Given recommended infection control measures, up to 380000 infections and 9000 deaths related to CAUTIs per year could be prevented in the USA. ${ }^{15}$

Unlike other countries, Australia has not recently conducted a national point prevalence study on HAIs. The last Australian national prevalence survey for nosocomial and community-acquired infections was conducted in $1984,{ }^{16}$ with authors reporting a prevalence of $6.3 \%$ for HAIs with UTIs contributing to $22 \%$ of infections. ${ }^{16}$ The most recent study to report the incidence of UTIs in Australia was conducted in two hospitals, with authors reporting an incidence of $1.66 \% .{ }^{17}$

To date, in Australia there is no specific national strategy and surveillance system in place to address HAUTIs and CAUTIs. ${ }^{18}{ }^{19}$ Several Australian States undertake surveillance activities for HAIs including the Victorian Hospital Acquired Surveillance Programme (VICNISS); South Australian Infection Control Service (SANIT); the Centre for Healthcare Related Infection Surveillance and Prevention (CHRISP) in Queensland ${ }^{18}{ }^{20}$; the Tasmanian Infection Prevention and Control Unit (TIPCU) and the Hospital Infection Surveillance program in Western Australia (HISWA). These surveillance programmes differ considerably, with variability in infections surveyed and level of participation by hospitals with no mandatory participation required for hospitals within these states except New South Wales. ${ }^{21}$ At present, there is no national or state level surveillance for HAUTIs in Australian hospitals.

To provide the foundation for a national point prevalence study and for a future prospective interventional study, we conducted a preliminary study in six Australian hospitals. The aims and objectives of this study were to (1) establish the point prevalence of HAUTIs and CAUTIs, (2) describe level and comprehensiveness of documentation related to care of urinary catheters, (3) compare two internationally accepted definitions in categorising patients with CAUTIs, namely the Health Protection Agency (HPA) ${ }^{22}$ and Centers for Disease Control and Prevention (CDC) $)^{23}$ definitions and (4) compare the sensitivity of microbiology laboratory data, coding data and clinical record documentation at identifying cases of HAUTIs and CAUTIs. It is expected that the findings from this study will provide policymakers and healthcare providers in Australia with HAUTI data to inform the development and implementation of targeted surveillance and high-impact HAUTI prevention programmes, as well as testing a process for point prevalence of HAUTI.

\section{METHODS}

Study design

Cross-sectional study.

\section{Setting and data sources/measurement}

Three publicly funded and three private hospitals in two Australian jurisdictions participated in the PPS. Two of the three publicly funded hospitals had greater than 400 beds each and similar case mix which included intensive care unit, $24 \mathrm{~h}$ emergency department, haematology/ oncology units, dialysis units, paediatrics/women and children, elective and emergency surgery. The third public hospital had fewer than 400 beds and no paediatric or dialysis services. One private hospital was a rehabilitation hospital and the other two provided acute medical and surgical services.

The survey was conducted over the first 6 months of 2013 in two phases. The first phase involved two public and two private hospitals and the data were collected concurrently over a single day at these sites. The second phase of the study was conducted in the remaining private and public hospital after additional funding had been obtained. Similar to phase 1, patient records were concurrently surveyed at both sites.

For each hospital, the survey was conducted using a standardised paper-based questionnaire developed by the researchers from the CAUTI toolkit resources of the CDC. ${ }^{24}$ On the day of the point prevalence study, demographic and clinical data were obtained from patients' notes and laboratory records. Data collected included age, sex, ward specialty, presence of urinary catheter and documentation of insertion and causative organism where appropriate of all eligible patients. For each patient who had a catheter inserted, documentation was reviewed to determine whether the need for the catheter was assessed daily, consistent with best practice recommendations. ${ }^{25}{ }^{26} \mathrm{~A}$ separate protocol paper provides more details of the study methods. ${ }^{27}$ 
The DRG (Diagnosis-Related Group) and ICD-10 (International Classification of Diseases Tenth revision) coding data were retrieved by the medical records departments approximately 2 months after completion of the PPS. Data from the standardised paper-based questionnaires were subsequently entered into a purpose designed Excel database and exported into a statistical software package for analysis.

\section{Participants}

Records of patients of all ages, hospitalised on the day of the point prevalence at the study sites, were eligible for inclusion, with some exceptions. Outpatients, patients in adult mental health units, patients categorised as maintenance care type (ie, patients waiting to be transferred to a long-term care facility) and those in the emergency department during the duration of the survey were excluded.

\section{Bias}

Inter-rater reliability was enhanced by development and use of a standardised training programme, with mastery being formally assessed prior to data collection, to reduce the possibility of information bias. ${ }^{27}$ The data were collected by trained research assistants who were all registered or enrolled nurses. Before the survey dates, all research assistants were provided with a training package and underwent $2 \mathrm{~h}$ of mandatory face-to-face training and assessment to assist them in collecting point prevalence data and to enhance inter-rater reliability in the application of HAUTI and CAUTI definitions and other survey procedures. The training package and programme were developed using the Health Protection Scotland Education and Training Events resources. ${ }^{28}$

\section{Study size}

All hospitalised persons in the participating organisation who met eligibility criteria on a given day were included in the study.

\section{Variables}

The main outcome measure was HAUTIs with CAUTI being specifically identified within this outcome. HAI status was defined as hospitalisation greater than $48 \mathrm{~h}$. HAUTIs and CAUTIs were ascertained by using two sets of criteria, those established by the HPA/European Centre for Disease Prevention and $\mathrm{Control}^{22}$ and by the $\mathrm{CDC}^{23}$ These definitions are complex; therefore, flow diagrams (available as online supplementary material) were provided to research assistants' to assist them with case definitions. ${ }^{27}$

All patients were ascribed one or more diagnosisrelated codes on discharge from hospital. These codes are known as the Australian Refined DRGs. This classification system enables a hospital's case mix to be described in a clinically meaningful way, enables subsequent use to identify resources required by the hospital and forms the basis for funding in some Australian
States and Territories. ${ }^{29}$ Our study collected ICD-10 codes for infection and ICD-10 Clinical Modification for procedures $^{30}$ to identify those relevant to UTIs and catheterisation.

\section{Statistical methods}

Data analysis was performed using IBM Statistics SPSS V.20. Descriptive analysis such as counts and percentages for categorical data and measures of central tendency and dispersion for continuous data was performed. The HAUTI and CAUTI point prevalences were calculated using the total patient population surveyed as the denominator. The sensitivity and positive predictive values of CDC and HPA surveillance definitions for HAUTI and CAUTI were compared. Cross tabulation and measures of association were applied using $\chi^{2}$ tests and Fishers exact test where appropriate to explore differences between public and private hospitals and factors significantly associated with HAUTI and CAUTI.

\section{RESULTS}

A total of six hospitals were surveyed over a 6-month period and all data have been aggregated. Subgroup analysis is limited to public and private hospital status to prevent potential identification of individual participating institutions.

\section{Participants}

A total of 1109 patients were surveyed on the designated days. Of these, $505(45.5 \%)$ were men and $604(54.5 \%)$ were women. The median age was 64 years (IQR 4279 years). Table 1 shows the results stratified by hospital type with 905 patients surveyed from the three public hospitals and 204 from the three private hospitals. The case mix of patients based on the DRG data varied across public and private hospitals with the majority of patients managed for diseases of the musculoskeletal system and connective tissue. This DRG was followed by diseases of the digestive system for the private hospitals and patients assigned codes based on factors influencing health status and other contacts with health services for the public hospitals such as patients attending follow-up visits and organ donors (table 1 ).

\section{Prevalence of UTI}

The overall prevalence of HAUTI was $1.4 \%(15 / 1109)$ and the prevalence of CAUTI was $0.9 \%$ (10). Staphylococcus aureus (20\%) and Candida species (20\%) were the most common pathogens identified among the patients with HAUTIs. Table 2 presents the microbial characteristics of all infections. Of the 1109 patients who were included in the survey, $1.1 \%$ met the CDC surveillance criteria for symptomatic UTI and $0.2 \%$ met the CDC criteria for asymptomatic UTI. One per cent of the patients met the microbiological HPA criteria and $0.2 \%$ the non-microbiological HPA criteria. There was one 


\begin{tabular}{|c|c|c|c|}
\hline Characteristic & $\begin{array}{l}\text { Private } \\
\text { hospitals } \\
n(\%) \\
n=204\end{array}$ & $\begin{array}{l}\text { Public } \\
\text { hospitals } \\
n(\%) \\
n=905\end{array}$ & $\begin{array}{l}\text { Total (\%) } \\
\mathrm{N}=1109\end{array}$ \\
\hline \multicolumn{4}{|l|}{ Age category (in years) } \\
\hline$<35$ & $21(10.3)$ & $210(23.2)$ & $231(20.8)$ \\
\hline $35-64$ & $46(22.5)$ & $292(32.3)$ & $338(30.5)$ \\
\hline $65-84$ & $82(40.2)$ & $299(33.0)$ & $381(34.4)$ \\
\hline$\geq 85$ & $55(27.0)$ & $104(11.5)$ & 159 (14.3) \\
\hline \multicolumn{4}{|l|}{ Gender } \\
\hline Male & $79(38.7)$ & $426(47.1)$ & $505(45.5)$ \\
\hline Female & $125(61.3)$ & 479 (52.9) & $604(54.5)$ \\
\hline \multicolumn{4}{|l|}{ Ward specialty } \\
\hline Surgery & $69(33.8)$ & $300(33.1)$ & 369 (33.3) \\
\hline General medicine & $55(27.0)$ & $273(30.2)$ & $328(29.6)$ \\
\hline General practice/rehabilitation/geriatric medicine & $37(18.1)$ & $100(11.0)$ & $137(12.4)$ \\
\hline Obstetrics/gynaecology & $17(8.3)$ & $86(9.5)$ & $103(9.3)$ \\
\hline Oncology & $17(8.3)$ & $55(6.1)$ & $72(6.5)$ \\
\hline Paediatrics & $7(3.4)$ & $63(7.0)$ & $70(6.3)$ \\
\hline High dependency unit & $0(0)$ & $28(3.1)$ & $28(2.5)$ \\
\hline Other (pain management) & $2(1.0)$ & $0(0)$ & $2(0.2)$ \\
\hline \multicolumn{4}{|l|}{ DRG } \\
\hline Diseases of the musculoskeletal system and connective tissue & $41(20.1)$ & $130(14.4)$ & $171(15.4)$ \\
\hline Factors influencing health status and other contacts with health services & $5(2.5)$ & $89(9.8)$ & $94(8.5)$ \\
\hline Diseases of the digestive system & $18(8.8)$ & $63(7.0)$ & $81(7.3)$ \\
\hline Diseases of the circulatory system & $8(3.9)$ & $65(7.2)$ & $73(6.6)$ \\
\hline Diseases of the respiratory system & $14(6.9)$ & $47(5.2)$ & $61(5.5)$ \\
\hline Pregnancy, childbirth and puerperium & $11(5.4)$ & $47(5.2)$ & $58(5.2)$ \\
\hline Diseases of the nervous system & $15(7.4)$ & $39(4.3)$ & $54(4.9)$ \\
\hline Newborns and other neonates & $16(7.8)$ & $27(3.0)$ & $43(3.9)$ \\
\hline $\begin{array}{l}\text { Major procedures where the principal diagnosis may be associated with } \\
\text { any major diagnostic category }\end{array}$ & $16(7.8)$ & $18(2.0)$ & $34(3.1)$ \\
\hline Diseases of the kidney and urinary tract & $8(3.9)$ & $25(2.8)$ & $33(3.0)$ \\
\hline Other ${ }^{*}$ & $38(18.6)$ & $133(14.7)$ & $171(15.4)$ \\
\hline Missingt & $14(6.9)$ & $222(24.5)$ & $236(21.3)$ \\
\hline \multicolumn{4}{|c|}{$\begin{array}{l}\text { *Diseases of the skin, subcutaneous tissue and breast; injuries, poisoning and toxic effects of drugs; diseases of the hepatobiliary system and } \\
\text { pancreas; neoplastic diseases (haematological and solid neoplasms); infectious and parasitic diseases; endocrine, nutritional and metabolic } \\
\text { diseases and disorders; diseases of the ear, nose, mouth and throat; diseases of the female reproductive system; diseases of the male } \\
\text { reproductive system; mental diseases and disorders; diseases of the blood and blood forming organs and immunological diseases; diseases } \\
\text { of the eye; burns. } \\
\text { tMissing DRG data include all patients in one public hospital. } \\
\text { DRG, Diagnosis-Related Group. }\end{array}$} \\
\hline
\end{tabular}

Table 2 Microbial characteristics for non-CAUTI HAUTIs and CAUTIs

\begin{tabular}{|c|c|c|c|c|c|}
\hline Type of organism & $\begin{array}{l}\text { Non-CAUTI } \\
\mathrm{N}=5\end{array}$ & $\begin{array}{l}\text { ICD-10 code } \\
\text { yes/no }\end{array}$ & $\begin{array}{c}\text { CAUTI } \\
\mathrm{N}=10\end{array}$ & $\begin{array}{l}\text { ICD code } \\
\text { yes/no }\end{array}$ & $\begin{array}{l}\text { TOTAL } \\
\mathrm{N}=15\end{array}$ \\
\hline \multicolumn{6}{|l|}{ Gram positive } \\
\hline Enterococcus species & 1 & No & 1 & No & 2 \\
\hline Staphylococcus aureus & 1 & Yes & 2 & 1 yes 1 no & 3 \\
\hline \multicolumn{6}{|l|}{ Gram negative } \\
\hline Escherichia coli & 0 & NA & 2 & Yes & 2 \\
\hline Klebsiella species & 0 & NA & 1 & No & 1 \\
\hline Proteus species & 2 & No & 0 & NA & 2 \\
\hline Pseudomonas species & 1 & No & 0 & NA & 1 \\
\hline \multicolumn{6}{|l|}{ Fungi } \\
\hline Candida species & 0 & NA & 3 & 1 yes 2 no & 3 \\
\hline Organism not listed & 0 & NA & 1 & Yes & 1 \\
\hline
\end{tabular}

CAUTI, catheter-associated urinary tract infection; HAUTI, healthcare-associated urinary tract infection; ICD, International Classification of Diseases; NA, not applicable. 
Table 3 Comparison of Centers for Disease Control and Prevention (CDC) and Health Protection Agency (HPA) surveillance definitions

\begin{tabular}{llll}
\hline & $\begin{array}{l}\text { CDC }^{*} \\
\text { positive }\end{array}$ & $\begin{array}{l}\text { CDC } \\
\text { negative }\end{array}$ & Total \\
\hline HPA positive & $11(1.0 \%)$ & $1(0.1 \%)$ & $12(1.1 \%)$ \\
HPA negative & $3(0.3 \%)$ & $1094(98.6)$ & $1097(98.9 \%)$ \\
Total & $14(1.3 \%)$ & $1095(98.7 \%)$ & $1109(100.0 \%)$ \\
\hline
\end{tabular}

The percentages represent the number of people identified as having a healthcare-associated urinary tract infection based on a specific criteria divided by the total number of people surveyed. ${ }^{*}$ For the purposes of calculation, the CDC definition was considered to be gold standard.

patient who had microbiological and nonmicrobiological HPA confirmation of UTI.

Tables 3 and 4 provide the comparison of surveillance definitions, the positive predictive value and sensitivity with the HPA definition classified as the 'test' and the CDC definition as the 'gold standard'.

\section{Pattern of catheter usage}

One-quarter $(26.3 \%)$ of all surveyed patients had a urinary catheter in place during the audit admission with the majority being indwelling catheters (88.7\%). Less than half of patients surveyed had appropriate documentation, such as designation of person inserting catheter $(28.8 \%)$ and reason for insertion (38.7\%; table 5). For patients with a catheter who had the reason for insertion stated that the majority of catheters were inserted for perioperative use for selective surgical procedures $(38.9 \%)$, acute urinary retention $(24.8 \%)$ and urinary output monitoring in critically ill patients $(22.1 \%)$.

Of the 292 patients who had a catheter in during the audit only $7(2.4 \%)$ patients were assigned ICD-10 codes by the medical records department as having a urinary catheter with $2(0.7 \%)$ coded as having a 'bladder catheter' during their admission.

\section{ICD-10 codes}

Eighty-six $(7.8 \%)$ patients were coded by the medical records department as having a UTI. This coding did not take into account whether they were healthcare associated or not. Eight of the 15 patients who were

Table 4 Estimates of the positive predictive value, sensitivity and Cls of the Health Protection Agency surveillance definition compared with the Centers for Disease Control and Prevention definition

\begin{tabular}{lll}
\hline Result & Value (\%) & $\mathbf{C l}$ \\
\hline Sensitivity & 78.57 & $(52.41$ to 92.43$)$ \\
Specificity & 99.91 & $(99.48$ to 99.98$)$ \\
Positive predictive value & 91.67 & $(64.61$ to 98.51$)$ \\
Negative predictive value & 99.73 & $(99.20$ to 99.91$)$ \\
Diagnostic accuracy & 99.64 & (99.08 to 99.86) \\
\hline
\end{tabular}

ascertained to have a HAUTI based on the CDC and HPA criteria (with 6 of these being CAUTI) were also coded by the medical records department with an ICD-10 code for UTI diagnosis.

\section{DISCUSSION}

There were four main findings from this study: the point prevalence of HAUTI was comparable to other studies; identification of poor standards of documentation; a suggestion that the CDC surveillance definition identified more patients with HAUTI compared with the HPA and that clinical coding data grossly underestimates the incidence of HAUTI. Each of these findings will now be explored in more detail.

The $1.4 \%$ HAUTI point prevalence and $0.9 \%$ CAUTI point prevalence for this study are consistent with previously published reported rates, nationally ${ }^{17}$ and internationally. ${ }^{31}$ While this prevalence may seem low, approximately $20-30 \%$ of all HAIs are UTIs. ${ }^{31} 32$ Extrapolating our data, we estimate that on any given day, there are approximately 1120 Australian inpatients with a HAUTI, assuming 80000 acute hospital beds in Australia. $^{33}$ In addition, a proportion of bacteraemias are associated with UTIs and these have an associated mortality. ${ }^{34-36}$ In the era of increasing antimicrobial resistance, particularly in Gram-negative organisms, patient outcomes have the potential to worsen, demonstrating a growing need for vigilance in infection prevention and HAUTI surveillance.

In this study, documentation relating to catheter insertion and management in all healthcare facilities in the study was poor. There are two main implications that follow from this-evidence-based practice and health economics. For evidence-based practice, the lack of documentation about who inserted catheter, catheter type and reasons for insertion would not inspire confidence in patients about the quality of care provided or compliance with evidence-based practice. For example, our survey evaluated documentation against national and international practice recommendations such as whether the ongoing need for a catheter is regularly reviewed. $^{9} 2526$ The biggest risk for UTI is duration of indwelling urinary catheter. ${ }^{9}$ While it is reasonable to assume that the need for the catheter was regularly renewed for some patients and simply not documented, it is also probable that review of the need for catheter was not undertaken for many. Minimising the number of patients with catheters and the duration of catheterisation could significantly reduce the incidence of UTIs and HAIs more generally. ${ }^{25}$ We have identified a potential gap in best practice which lends itself to future prospective interventional studies targeting improvements in urinary catheter care. We identified a further issue with poor documentation as less than $10 \%$ of urinary catheter usage was identified by ICD-10 coding. This has potential implications for funding, depending on the funding model applied. 
Table 5 Catheter information

\begin{tabular}{|c|c|c|c|}
\hline Characteristic & $\begin{array}{l}\text { Private hospitals (\%) } \\
\mathrm{n}=60\end{array}$ & $\begin{array}{l}\text { Public hospitals (\%) } \\
\mathrm{n}=232\end{array}$ & $\begin{array}{l}\text { Total (\%) } \\
\mathrm{N}=292\end{array}$ \\
\hline \multicolumn{4}{|l|}{ Catheter at any time during this admission } \\
\hline Yes & $60(29.4)$ & $232(25.6)$ & $292(26.3)$ \\
\hline No & $144(70.6)$ & $673(74.4)$ & $817(73.7)$ \\
\hline \multicolumn{4}{|l|}{ Presence of catheter } \\
\hline Currently in situ & $29(48.3)$ & $146(62.9)^{\star}$ & $175(59.9)$ \\
\hline Catheter inserted but removed during admission & $31(51.7)$ & $85(36.7)$ & $116(39.7)$ \\
\hline Intermittent & $0(0)$ & $1(0.4)$ & $1(0.4)$ \\
\hline \multicolumn{4}{|l|}{ Catheter location } \\
\hline Indwelling & $54(90.0)$ & $205(88.4)$ & $259(88.7)$ \\
\hline Supra pubic & $4(6.6)$ & $10(4.3)$ & $14(4.8)$ \\
\hline Intermittent & $0(0)$ & $2(0.9)$ & $2(0.7)$ \\
\hline Both indwelling and supra pubic & $1(1.7)$ & $0(0)$ & $1(0.3)$ \\
\hline Not documented & $1(1.7)$ & $15(6.4)$ & $16(5.5)$ \\
\hline \multicolumn{4}{|l|}{ Catheter type } \\
\hline Silver alloy & $0(0)$ & $1(0.4)$ & $1(0.3)$ \\
\hline Silicone & $7(11.7)$ & $55(23.7)$ & $62(21.2)$ \\
\hline Antimicrobial & $0(0)$ & $0(0)$ & $0(0)$ \\
\hline Foley & $0(0)$ & $19(8.2)$ & $19(6.5)$ \\
\hline Latex & $0(0)$ & $2(0.9)$ & $2(0.7)$ \\
\hline Other & $0(0)$ & $11(7.8)$ & $11(3.8)$ \\
\hline Not documented & $53(88.3)$ & $144(62.1)$ & $197(67.5)$ \\
\hline \multicolumn{4}{|l|}{ Catheter size (French grade) } \\
\hline 6 & $0(0)$ & $1(0.4)$ & $1(0.3)$ \\
\hline 10 & $0(0)$ & $1(0.4)$ & $1(0.3)$ \\
\hline 12 & $16(26.7)$ & $16(6.9)$ & $32(11.0)$ \\
\hline 14 & $10(16.7)$ & $54(23.3)$ & $64(22.0)$ \\
\hline 16 & $8(13.3)$ & $19(8.2)$ & $27(9.2)$ \\
\hline 18 & $0(0)$ & $3(1.3)$ & $3(1.0)$ \\
\hline 20 & $2(3.3)$ & $2(0.9)$ & $4(1.4)$ \\
\hline 22 & $0(0)$ & $1(0.4)$ & $1(0.3)$ \\
\hline 24 & $1(1.7) \dagger$ & $0(0)$ & $1(0.3)$ \\
\hline Not documented & $24(40.0)$ & $135(58.2)$ & $159(54.5)$ \\
\hline \multicolumn{4}{|l|}{ Inserted by } \\
\hline Nurse & $5(8.3)$ & $46(19.8)$ & $51(17.5)$ \\
\hline Doctor & $13(21.7)$ & $18(7.8)$ & 31 (10.6) \\
\hline Other (student) & $1(1.7)$ & $1(0.4)$ & $2(0.7)$ \\
\hline Not documented & $41(68.3)$ & $167(72.0)$ & $208(71.2)$ \\
\hline \multicolumn{4}{|l|}{ Reason for insertion stated } \\
\hline Yes & $36(60.0)$ & 77 (33.2) & $113(38.7)$ \\
\hline No & $24(40.0)$ & $155(66.8)$ & $179(61.3)$ \\
\hline \multicolumn{4}{|l|}{ Cleaning solution } \\
\hline Chlorhexidine & $0(0)$ & $1(0.4)$ & $1(0.3)$ \\
\hline Unknown & $60(100)$ & $231(99.6)$ & $291(99.7)$ \\
\hline \multicolumn{4}{|l|}{ Ongoing need for catheter reviewed (days) } \\
\hline 0 & $34(56.7)$ & $157(67.7)$ & $191(65.4)$ \\
\hline 1 & $10(16.7)$ & $35(15.1)$ & $45(15.4)$ \\
\hline $2-3$ & $5(8.3)$ & $24(10.3)$ & $29(9.9)$ \\
\hline $4-5$ & $1(1.7)$ & $3(1.3)$ & $4(1.4)$ \\
\hline$>5$ & $0(0)$ & $3(1.3)$ & $3(1.0)$ \\
\hline Not documented & $10(16.7)$ & $10(4.3)$ & $20(6.8)$ \\
\hline
\end{tabular}

In this study, the CDC surveillance definition identified more patients with HAUTI than the HPA definition. The difference in positive predictive value, however, was not statistically significant. Research assistants responsible for data collection overwhelmingly reported that the HPA definition was easier to use. Therefore, while the CDC definition is recognised as the gold standard, ${ }^{37}$ and HPA in our study had a lower capture rate, 
use of the HPA definition is still likely to predict $91.7 \%$ (CI $64.6 \%$ to $98.5 \%$ ) of infections diagnosed through use of the CDC definition. Therefore, given the much greater ease of use of the HPA definition, we recommend the use of the HPA definition in future point prevalence studies. Any potential issue of underestimating the incidence of HAUTI using the HPA surveillance definition is less important where data are used in a quality improvement framework, as these data can be used to inform and evaluate interventions ${ }^{38}$ rather than for diagnostic purposes or for performance management (ie, trends overtime being most important). Other authors have commented that prospective UTI surveillance is costly and time consuming to conduct $^{39}{ }^{40}$; therefore, we explored alternatives to prospective UTI surveillance by comparing our prevalence data with postdischarge coding data. Australian coding data do not distinguish between HAI cases and non-HAI cases. This is unlike the US coding data which provide a present on admission indicator code to inpatients helping to identify hospital-acquired infections. ${ }^{41}$ In our study, ICD coding missed $50 \%$ of HAUTIs. If ICD-10 codings are used to determine the incidence of HAUTI, for reporting purposes our study suggests that such a method will grossly underestimate the number of infections, with implications for funding arrangements. This finding has also been found for other infections. ${ }^{42}$

\section{RECOMMENDATIONS FOR PRACTICE, POLICY AND RESEARCH}

To enable the reduction of HAIs related to the genitourinary tract, it is important that all healthcare facilities have appropriate policies and protocols for insertion of either a urethral or supra pubic catheter. It is important that these policies and protocols are evidence based. However, prior to inserting a catheter, the question of whether the patient requires this procedure should be raised. If the decision is made to insert a catheter, then consideration should be given to the size of the catheter to insert, the reason for the insertion and duration of time that the catheter will be in place to allow timely removal of the catheter. All information relating to the catheter and its care should also be documented in the notes (this could be in the form of a sticker to be easily found in the notes) and on the care plan.

Documentation by medical and nursing staff is important for the day-to-day infection prevention and control and to alert staff to ensure timely removal of urinary catheters. If a CAUTI is diagnosed then documentation should include: causative organism, what antibiotics have been started and whether the antibiotics are appropriate to treat that microorganism. Other relevant notes are actions taken, such as removal or replacement of the catheter. One potential way of improving compliance with clinical guidelines and documentation at the insertion and maintenance phases of catheter care is the use of a checklist or 'bundle' approach. ${ }^{43}$
To improve health outcomes for patients, it is important to continue exploration of ways to identify and reduce HAUTIs and CAUTIs. We have shown it is feasible to conduct prevalence studies across six health institutions, and funding should be sought for a national point prevalence of UTIs as demonstrated by countries already undertaking this. ${ }^{4}$ Analysing national point prevalence data will provide a baseline for intervention studies that test care bundles to reduce HAUTIs and their sequelae. ${ }^{43}$

Currently, it appears that ICD-10 coding is not a reliable way of monitoring prevalence of HAUTI, at least in some healthcare facilities. Our findings were consistent with other HAI coding. ${ }^{42}$ This potential under-reporting of infections has implications for policy and healthcare reimbursement, although in some US jurisdictions, healthcare facilities are penalised for HAIs rather than being reimbursed. ${ }^{44}$ We recommend that facilities undertake audits to compare clinical and coding data periodically.

There are some limitations in our study. The survey was conducted in only six hospitals within two states and territories limiting the generalisability of the results. However, there were significant findings enabling recommendations for a future national point prevalence study to be made. Another limitation of our study is the reliance on clinical records and not direct diagnosis. This was overcome by using research assistants with some prior clinical and infection control knowledge, for example, registered nurses, for data collection. The research assistants were adequately trained and the outcome of the training was evaluated by post training case study assessments. ${ }^{27}$ Such a process also enhanced inter-rater reliability. There were no previous HAUTI and CAUTI rates for comparison within the study sites as they had not collected this type of data before. As earlier stated, the findings can now be used to make recommendations for conducting PPS in a standardised manner to facilitate comparisons over time within individual health facilities. The aggregation of data from all participating hospitals for analysis may be a further limitation. The size and scope of services in these hospitals varies and this in turn presents variations in risk. Regardless, the process we employed is common in point prevalence studies, which only capture data at a specific point in time. ${ }^{8}$ Despite the study limitations, this survey has identified some priority areas including efficacy of documentation practices related to care of urinary catheters which are key to preventing CAUTIs. There were also no obvious sources of bias.

\section{CONCLUSION}

To tackle the issue of CAUTIs and other HAIs in Australia, it is imperative to develop a national surveillance system based on validated methods and definitions which have been found to be effective in other developed countries. This study provides a foundation for the development of a national infection control initiative in our rapidly evolving healthcare environment and associated challenges with drug resistance. 
Author affiliations

${ }^{1}$ School of Nursing, Midwifery and Paramedicine, Australian Catholic University, Canberra, Australian Capital Territory, Australia

${ }^{2}$ Faculty of Nursing and Health, Avondale College, Wahroonga, New South Wales, Australia

${ }^{3}$ Department of Infection Prevention and Control, Canberra Hospital and Health Services, Canberra, Australian Capital Territory, Australia

Acknowledgements Thanks to Professor Peter Collignon (Director of Infectious Diseases and Microbiology, Canberra Hospital and Health Services) and staff of the participating hospitals for their assistance in this research project. Thanks also to Professor Jenny Peat, Honorary Professor, Australian Catholic University, for statistical advice.

Contributors All authors contributed to the design of study and development of instruments. BM, WB and OF supervised data collection. OF and $A G$ conducted initial data analysis. All authors contributed to further data analysis and manuscript preparation.

Funding This work was supported by a Covidien 2012 Infection Control Scholarship and a 2013 Australian Catholic University Faculty of Health Sciences Research Grant.

Competing interests None.

Ethics approval Australian Catholic University.

Provenance and peer review Not commissioned; externally peer reviewed.

Data sharing statement No additional data are available.

Open Access This is an Open Access article distributed in accordance with the Creative Commons Attribution Non Commercial (CC BY-NC 3.0) license, which permits others to distribute, remix, adapt, build upon this work noncommercially, and license their derivative works on different terms, provided the original work is properly cited and the use is non-commercial. See: http:// creativecommons.org/licenses/by-nc/3.0/

\section{REFERENCES}

1. Umscheid $\mathrm{C}$, Mitchell M, Doshi J, et al. Estimating the proportion of healthcare-associated infections that are reasonably preventable and the related mortality and costs. Infect Control Hosp Epidemiol 2011;32:101-14.

2. Allegranzi B, Nejad SB, Combescure C, et al. Burden of endemic health-care-associated infection in developing countries: systematic review and meta-analysis. Lancet 2011;377:228-41.

3. Klompas M, Yokoe D. Automated surveillance of healthcare-associated infections. Clin Infect Dis 2009;48:1268-75.

4. European Centre for Disease Prevention and Control (ECDC). Point prevalence survey of healthcare-associated infections and antimicrobial use in European acute care hospitals 2011-2012. Stockholm: ECDC, 2013

5. Kohn LT, Corrigan JM, Donaldson MS. To err is human: building a safer health system. Washington, DC: National Academy Press, 1999.

6. National Health and Medical Research Council. Australian Guidelines for the Prevention and Control of Infection in Healthcare 2010. http://www.nhmrc.gov.au/_files_nhmrc/publications/ attachments/cd33 complete.pdf (accessed 25 Jul 2013).

7. Gravel D, Taylor $\mathrm{G}$, Ofner $\mathrm{M}$, et al. Point prevalence survey for healthcare-associated infections within Canadian adult acute-care hospitals. J Hosp Infect 2007;66:243-8.

8. Smyth ETM, Mcllvenny G, Enstone JE, et al. Four Country Healthcare Associated Infection Prevalence Survey 2006: overview of the results. J Hosp Infect 2008;69:230-48.

9. Gould CV, Umscheid CA, Agarwal RK, et al. Guideline for prevention of catheter-associated urinary tract infections 2009. Infect Control Hosp Epidemiol 2010;31:319-26.

10. Elvy J, Colville A. Catheter associated urinary tract infection: what is it, what causes it and how can we prevent it? J Infect Prev 2009;10:36-41.

11. Jain $\mathrm{P}$, Parada JP, David A, et al. Overuse of the indwelling urinary tract catheter in hospitalized medical patients. Arch Intern Med 1995;155:1425-9.

12. Munasinghe $\mathrm{R}$, Yazdani $\mathrm{H}$, Siddique $\mathrm{M}$, et al. Appropriateness of use of indwelling urinary catheters in patients admitted to the medical service. Infect Control Hosp Epidemiol 2001;22:647-9.
13. Saint S, Wiese J, Amory JK, et al. Are physicians aware of which of their patients have indwelling urinary catheters? Am J Med 2000;109:476-80.

14. Warren JW. Catheter-associated urinary tract infections. Int $J$ Antimicrob Agents 2001;17:299-303.

15. Umscheid C, Mitchell M, Agarwal R, et al. Mortality from reasonably-preventable hospital acquired infections. Included in written testimony by the Society of Healthcare Epidemiology of America for the Committee on Oversight and Government Reform Hearing on Healthcare-associated Infections: A Preventable Epidemic, chaired by Henry A. Waxman, April 16, 2008 (Congressional Testimony). Washington, DC 2008.

16. McLaws ML, Gold J, King K, et al. The prevalence of nosocomial and community-acquired infections in Australian hospitals. Med $J$ Aust 1988;149:582-90.

17. Graves N, Tong E, Morton AP, et al. Factors associated with health care-acquired urinary tract infection. Am J Infect Control 2007;35:387-92.

18. Reed CS, Gorrie G, Spelman D. Hospital infection control in Australia. J Hosp Infect 2003;54:267-71.

19. Cruickshank M, Ferguson J, Bull A. Reducing harm to patients from health care associated infection: the role of surveillance. Chapter 3 : surgical site infection-an abridged version. Healthcare Infect 2009;14:109-14.

20. McLaws M, Taylor P. The hospital infection standardised surveillance (HISS) programme: analysis of a two-year pilot. $J$ Hosp Infect 2003;53:259-67.

21. Richards M, Russo P. Surveillance of hospital-acquired infections in Australia-one nation, many states. J Hosp Infect 2007;65:174-81.

22. Health Protection Agency. Fourth National Point Prevalence Survey on Healthcare Associated Infections and First National Point Prevalence Survey on Antimicrobial Use and Quality Indicators in England 2011. http://www.hpa.org.uk/webc/HPAwebFile/HPAweb_C/ 1296687778967 (accessed 25 Jul 2013)

23. Centres for Disease Control and Prevention. NHSN Patient Safety Component Manual 2012. http://www.cdc.gov/nhsn/pdfs/pscManual/ 7pscCAUTlcurrent.pdf (accessed 25 Jul 2013).

24. Centers for Disease Control and Prevention. Urinary Tract Infection 2012. http://www.cdc.gov/nhsn/forms/57.114 UTI BLANK.pdf (accessed 25 Jul 2013).

25. Mitchell B, Ware C, McGregor A, et al. ASID (HICSIG)/AICA Position Statement: preventing catheter-associated urinary tract infections in patients. Healthcare Infect 2011;16:45-52.

26. Tenke P, Kovacs B, Bjerklund JTE, et al. European and Asian guidelines on management and prevention of catheter-associated urinary tract infections. Int J Antimicrob Agents 2008;31:68-78.

27. Mitchell B, Gardner A, Beckingham W, et al. Healthcare associated urinary tract infections: a protocol for a national point prevalence study. Healthcare Infect 2014;19:26-31.

28. Health Protection Scotland. Catheter associated urinary tract infection surveillance for acute settings. Glasgow: Health Protection Scotland, 2012.

29. Australian Institute of Health and Welfare. Australian Refined Diagnosis Related Groups (AR-DRGs). Canberra: Australian Government, 2013. http://www.aihw.gov.au/ar-drg-data-cubes/ \#ARDRGs (accessed 25 Jul 2013).

30. Independent Hospital Pricing Authority (IHPA). Australian Refined Diagnosis Related Groups (Version 6.0). Australian Government, 2008.

31. Zarb P, Coignard B, Griskeviciene J, et al. The European Centre for Disease Prevention and Control (ECDC) pilot point prevalence survey of healthcare-associated infections and antimicrobial use. Euro Surveill 2012;17:46.

32. Humphreys H, Newcombe RG, Enstone J, et al. Four country healthcare associated infection prevalence survey 2006: risk factor analysis. J Hosp Infect 2008;69:249-57.

33. Australian Institute of Health and Welfare. How many beds are there? Canberra: Australian Government, 2013. http://www.aihw.gov. au/haag09-10/number-of-beds/ (accessed 25 Jul 2013).

34. Collignon P, Dreimanis D, Ferguson J, et al. Bloodstream infection. In: Cruickshank M, Ferguson J. eds Reducing harm to patients from health care associated infection: the role of surveillance. Australian Commission on Safety and Quality in Health Care, 2008:53-89.

35. Wisplinghoff $\mathrm{H}$, Bischoff $\mathrm{T}$, Tallent SM, et al. Nosocomial bloodstream infections in US hospitals: analysis of 24,179 cases from a prospective nationwide surveillance study. Clin Infect Dis 2004;39:309-17.

36. Platt R, Polk FB, Murdock B, et al. Mortality associated with nosocomial urinary-tract infection. N Engl J Med 1982;307:637-42.

37. Greene L, Marx J, Oriola S. An APIC guide to the elimination of catheter-associated urinary tract infections (CAUTIs): developing and applying facility-based prevention interventions in acute and long-term care settings 2008. http://www.apic.org/Resource_/ 
EliminationGuideForm/c0790db8-2aca-4179-a7ae-676c27592de2/ File/APIC-CAUTI-Guide.pdf (accessed 21 Oct 2013).

38. Mitchell BG, Gardner A, McGregor A. Healthcare-associated infections: getting the balance right in safety and quality $\mathrm{v}$. public reporting. Aust Health Rev 2012;36:365-6.

39. Brown C, Richards M, Galletly T, et al. Use of anti-infective serial prevalence studies to identify and monitor hospital-acquired infection. J Hosp Infect 2009;73:34-40.

40. King C, Garcia Alvarez L, Holmes A, et al. Risk factors for healthcare-associated urinary tract infection and their applications in surveillance using hospital administrative data: a systematic review. $J$ Hosp Infect 2012;82:219-26.

41. Centers for Medicare and Medicaid Services. Present on admission $(P O A)$ indicator reporting by acute inpatient prospective payment system (IPPS) hospitals 2012. http://www.cms.hhs.gov/ HospitalAcqCond (accessed 21 Oct 2013)

42. Ong CW, Roberts JL, Collignon PJ. Long-term survival outcome following Staphylococcus aureus bacteraemia. Healthcare Infect 2013;18:102-9.

43. Saint S, Olmsted RN, Fakih MG, et al. Translating health careassociated urinary tract infection prevention research into practice via the bladder bundle. Jt Comm J Qual Patient Saf 2009;35:449-55.

44. Saint S, Meddings JA, Calfee D, et al. Catheter-associated urinary tract infection and the Medicare rule changes. Ann Intern Med 2009;150:877-84.

45. Wald HL, Kramer AM. Nonpayment for harms resulting from medical care. JAMA 2007;298:2782-4. 